\title{
VAN HOËVELL'S ARCHAEOLOGISCHE REIS IN MIDDEN-JAVA VAN 1840.
}

DOOR

\author{
D. G. P. ROUPFAER.
}

Tot nog toe meent men, dat een anonymus in 1839 een reis maakte van Batavia naar Jogja, en terug, waarbij hij zeer groote aandacht schonk aan de oudheden op den Diëng, die in Jogja, en in Kðdoe, neergelegd in zijn "Losse aanteekeningen, gehouden op eene reis over Java, in 1839, afgedrukt in het Tijdschrift voor Ned.-Indië, 1860 , I ${ }^{\circ}$ Deel, p. 171-188, en 203-230.

Voorts weet men, dat alweer een anonymus op 24-26 Mei 1840 een bezoek bracht aan den Boroboedoer, van Magelang uit, waarvan hij een voortreffelijke beschrijving gaf, in 1858 pas afgedrukt in hetzelfde Tijdschrift, $\mathrm{II}^{\mathrm{e}}$ Deel, p. 105-115, met de uitdrukkelijke vermelding: "(Uit een reis-journaal)", en een inleiding tot die beschrijving, door den Redacteur van dat tijdschrift, Dr. W. R. vaN HoËvElL; een en ander onder den titel ¿De tempel van Boro Boedoer in de residentie Kadoe».

En een jaar te voren, in 1857 , was evenzeer van een anonymus in datzelfde tijdschrift, I ${ }^{\mathrm{e}}$ Deel, p. 301-328, afgedrukt geworden, alweder met de vermelding: "(Fragment uit een Reisverhaal),, een beschrijving van de Garěb̌̌g Moeloed te Jogja met verwante onderwerpen, onder den titel «Djokdjokarta. Garebek Moeloed *, met een plaat. Het jaar van bijwonen van dit feest wordt in 't verhaal niet vermeld.

Hieronder zal ik nu aantoonen, dat deze drie stukken één en denzelfden oorsprong hebben: het Dagboek van VAN HoËvELLzelf over zijn reis Batavia-Jogja-Magělang en terug, van Aprileinde Mei 1840. Dat dus de pas in 1860 afgedrukte «Losse Aanteekeningen, over die reis door hem als Redacteur van het tijdschrift en schrijver van het Journaal, met opzet en tot bijster-making van zijne lezers, zijn geäntedateerd op 1839 . 
De sleutel tot herkenning van den anonymus der "Losse Aanteekeningen" uit zoogenaamd 1839 ligt in 't begin van het verhaal. Op 9 April was hij uit Batavia vertrokken, en op den $15^{\mathrm{en}}$, via Bandoeng, Soemědang, Cheribon, aangekomen te Tegal. Hier ontmoet hij den Regent, die hem bij het schatten van zijn leeftijd, naar Javaansche zede van beleefdheid, voor ouder aanziet den hij lijkt, en hem "een goeden veertiger» acht. De anonymus lacht witjes, daar hij knaauwelijks zes-en-twintig jaren kon halen. (p. 173); de Regent merkt het, en schat hem nu, wellevend, "zeker de vijftig reeds voorbij».

Dit op 15 $5^{\text {en }}$ April 1839 (zoogenaamd). Van Hoëvell was geboren den $15^{\text {en }}$ Juli 1812 , dus zoude toen 26 jaar en 9 maand zijn geweest. Men heeft den auteur al half te pakken, doch wantrouwt geen oogenblik het jaar 1839. Maar... ook hier hebben we te doen met een terugschuiving van een jaar in leeftijd. Want in den laten avond van 10 Mei 1839 (zoogenaamd) komt hij te Jogja, als gast van den Resident VALCK (dien hij "VALK , noemt; p. 225); zie toch p. 212. Ook nu is er bij ons nog geen argwaan; want F. G. VALCK was ten tweeden male van 14 Dec. 1838-Juli 1841 Resident van Jogja, na het van Maart 18315 Juli 1838 reeds te zijn geweest; 10 Mei 1839 of 10 Mei 1840 passen in dit verband even goed. Doch o wee voor den anonymus, ... eenige regels verder verheugt hij zich zeer over het feit "dat de geboorte van Moнammed ("garebek moeloed») den $14^{\text {den }}$ Mei zou gevierd worden" (p. 212-213). Nu viel Gareběg Moeloed in 1839 op $26 \mathrm{Mei}$; in 1840 evenwel op $14 \mathrm{Mei}$. Men ziet ineens de opzettelijke verandering in het jaar der Losse Aanteekeningen, en weet dat de auteur, toen de Regent van Tegal op 15 April (1840) te voren zijn leeftijd schatte, goed 27 jaar oud was, niet "naauwelijks zes-en-twintig».

$\mathrm{Na}$ die woorden van den auteur over het vieren van Garěběg Moeloed te Jogja op 14 Mei, verwacht men een beschrijving van dit feest. Maar neen. De Redactie van het Tijdschrift voor Ned.-Indië (= Dr. W. R. vaN HoËvell!) zet hier bovenaan p. 213 twee rijen stippels, en onderaan deze noot: "Eene uitvoerige beschrijving van dit feest gaven wij reeds in een artikel van het Tijdschrift voor Nederlandsch Indië 19de jaargang [1857] I, 301 enz., zoodat de beschrijving daarvan in dit reisverhaal achterwege kan blijven.. We weten nu ineens, dat de beschrijving van gezegd Moeloed-feest uit 1857 slaat op de viering 
dd. 14 Mei 1840 te Jogja, bijgewoond door dezen zelfden auteur, die zich reeds voor drie kwart begint te ontpoppen als Van Hoëvell-zelf ${ }^{1}$.

De anonymus der Losse Aanteekeningen van kwansuis 1839 , terecht 1840, reist echter verder, na in Jogja's omgeving tal van oudheden bezocht en degelijk beschreven te hebben (p. 213 -224), en de bronzencollectie van zijn gastheer "resident VALK" kortelijk te hebben vermeld; waarbij een Redactie-noot memoreert den aankoop dezer collectie door het Bataviaasch Genootschap "later»; versta: in 1843 (p. 225-226). ${ }^{2} \mathrm{Hij}$ vertrekt 21 Mei van Jogja naar Magělang, hier zijn intrek weer nemende in het «residentie-huis» (p. 227); dat wil zeggen: gast wezende van den Resident van Kědoe, C. L. Hartmann, die dit was van $1832-1843$. Hij is vervuld van verlangen om van hier den "Boro Boedoer» te bezoeken; wat hij er over had vernomen en in losse beelden er reeds van had gezien, deden hem "naar die klassieke plaats reikhalzen» (p. 228). Verheugd is hij dan ook, dat hij "den 24 Mei aan dit verlangen voldoen kon".

De argelooze Redactie, zegge Dr. W. R. VAN HoËvell, laat hier drie regels stippels volgen, en deze noot: « Er is in den laatsten tijd, ook in dit Tijdschrift, zoo veel over Boro Boedoer geschreven, dat wij de in het handschrift volgende aanteekeningen daarover meenen achterwege te kunnen laten; te meer, dewijl geene nieuwe bijzonderheden daarin voorkomen.»

Dit boerenbedrog door den Baron-Dominé-Doctor-Redacteur VAN HOËVELL is kostelijk. "In het handschrift» van "1839, (lees 1840) komen omtrent «Boro Boedoer.... geene nieuwe bijzonderheden voor»»....; zegt $U$ dat wèl! Want 2 jaar te voren had Uzelf in $U w$ eigen tijdschrift uit $U w$ eigen handschrift en

1 Dat deze beschrijving van een Jogjasche Garĕbĕg Moeloed moest vallen tusschen 1833 en 1854, blijkt uit het noemen van Pangeran Adipati Nåtâprådjå als een van den Sultan onafhankelijken Prins. Deze werd dit op 24 Dec. 1832, en stierf 15 Nov. 1854. De auteur dezer beschrijving.... logeerde bij den Resident; maar diens naam noemt hij niet; den dag vóór Garĕbĕg stelde deze hem aan den Hoofd-panghoeloe voor als den "pandita besar" van Batavia.

2 N.l. na den dood van Valek, die, in 1841 met verlof gegaan wegens ziekte, te Voorburg op 22 April 1842 aan een slepende kwaal was overleden. Diens neef (oomzegger) H. Hope Loddox te Batavia, heeft toen, als executeurtestamentair van Valck, de bronzencollectie aan het Bataviaasch Genootschap voor $f$ 4500. - verkocht uit Valck's op Java achtergelaten kisten (pers. meded. Mr. Th. R. Valck Lucassen te Driebergen; en verg. Verhand. Bat. Gen. XIX, 1843 , p. XLIV-XLV). Dit werd de grondslag der Batavia-verzameling. 
reisjournaal afgedrukt Uw persoonlijk bezoek aan Boroboedoer, dat - met daarlating van een ietwat misleidende inleiding over een cons toegezonden(!) opstel» (p. 105), en eenig ander voorwerk - aanheft aldus :

«Den 24 Mei 1840 verliet ik Magelan ». (T. v. N.-I. 1858. II, p. 107)!

Hierbij zal ik het laten, wat de herkenning der 3 anonymi betreft. Begrijpt men eenmaal dat deze allen de drie-eenheid VAN HOËVELL representeeren in 1840, en niemand anders - niet dus b.v. Ds. BudDinGH, welke in 1838 Jogja en Kĕdoe had bezocht; nog minder Ds. BRUmund, welke pas op 14 Juli 1841 te Batavia aan wal stapte - , dan vindt men hem telkens in alle drie de opstellen terug: hij logeert bij Residenten; hij spreekt telkens over godsdienst, en het gebrek daaraan bij tal van verschijnselen; eenige zinnen uit de stukken van 1857 en 1858 vindt men letterlijk of bijna letterlijk terug in de publicatie van 1860 , juist daar waar de teksten in de kern der zaken aaneensluiten ${ }^{1}$; de auteur is ook vol belangstelling voor oudheden, zóózeer, dat men zijn reis naar Bagělen, Jogja en Kědoe in April-Mei 1840 gerust een archaeologische reis mag noemen.

Achtereenvolgens beschreef hij in zijn Losse Aanteekeningen, uitgave 1860, aangevuld met de publicatie van 1858: Diëng (25-28 April '40; p. 182-187); Pasar Gẹde (15 Mei; p. 213 -214); de Prambanan-tempels, met $\mathrm{Tj}$. Loemboeng, en $\mathrm{Tj}$. Sewoe (18 Mei; p. $214-219$; helaas met supprimeering der beschrijving van $\mathrm{Tj}$. Sewoe ${ }^{2}$, en vervanging door 3 rijen tittels); de zgn. Kraton van Ratoe Båkå, Tj. Sari, en Tj. Kali Běning (19 Mei; p. 220-224); de bronzencollectie-Valck $\left(20 \mathrm{Mei}^{3}\right.$ p. $225-$

1 En wel regel 5-15 op p. 213 in 1860 ("vroeger-opgeleverd") = regel $15-1$ v.o. op p. 307 in 1857 ; en r. $4-1$ v. o. op p. 227 plus r. $1-5$ op p. 228 ('Tusschen-Boro Boedoer') = r. 14-22 op p. 107 in 1858.

3 Dit verraadt zich op p. 220, alwaar het heet: „Waarom vonden wij dertien Boeddha-beelden te Tjandi Sowoe allen zonder hoofden, en sommigen zonder armen?"

Ook het relaas der terugreis, met vertrek uit Magĕlang dd. 29 Mei 1840 (p. 230), dan langs de rivier Pabelan, en, blijkbaar via Kletjå, over het zadel tusschen Mĕrapi en Mĕrbaboe naar Solo, is weggelaten.

3 Nota Bene: op 11 Mei 1840 (den dag, nadat Van Hoëvell te Jogja zijn gast was geworden, cn 10 dagen vóór diens vertrek) sloot Resident VALCK af zijne "Gedachten over de Ruïnen van de Hindoesche Godsdienst, welke op Java gevonden worden", afgedrukt in het T. v. N.-I $3^{\text {en }}$ jrg. (1840), dl. I, p. 177-203, waarin p. 197-201 over zijn 178 stuks, sinds 1830 verzamelde, bronzen. Redacteur van dit Tijdsohrift was toen: vaN HoËveLL! 
226); en ten slotte uitvoerig en allerbest den Boroboedoer (24-27 Mei; uitgave 1858). Daartusschen valt dan de Garěběg Moeloed (14 Mei; uitgave 1857), ingeleid door een romantisch verzinsel, zooals men uit den tekst van 1860 , p. 212 , kan bewijzen.

Alle teekens $* * *$ in het $\mathrm{II}^{\mathrm{e}}$ Deel van den *Inventaris der Hindoe-oudheden, (1918; Rapporten O. D. 1915) kunnen dus vervangen worden door den naam vaN HOËvELL, onder verbetering van het jaartal 1839 in 1840; en in de Monografie van Dr. KRom over den Boroboedoer (1919) mag de anonymus uit 1840 van nu af vereenzelvigd worden met dezen, met groote onderscheiding te noemen, grondlegger der Bataviasche archaeologische verzameling.

\section{NASCHRIFT.}

Het bovenstaande was reeds geschreven, toen ik me pas bedacht om eens den bundel schetsen en verhalen na te slaan, welken VAN HoËVELL onder zijn vollen naam in 1860 het licht deed zien met den titel "Uit het Indische leven». Het voorbericht is gedateerd 's Hage, 1 Nov. 1860, dus hetzelfde jaar als de publicatie van het Reisjournaal, hierboven besproken, in het Tijdschrift voor Ned.-Indië; de uitgever van beide (Joh. Noman en Zoon, Zalt-Bommel) was dezelfde; een tweede druk, evenzeer onder des auteurs vollen naam, verscheen in 1865 te Amsterdam.

En zie, - daar paradeert op p. 189-246 van den $1^{\text {en }}$ druk hetzelfde stuk "Garebek Moeloed», dat anoniem reeds in het T. v. N.-I. van 1857 was verschenen! Twijfel is hier dus uitgesloten ${ }^{1}$.

1 De uitvoerige noot, welke vaN HoËvell in den druk van 1857 op p. 3І3 plaatste over een geval dat bij de Garĕbĕg Moeloed te Soerakarta in 1846 plaats had gehad, aan den toenmaligen Resident zijn standplaats kostte, en in de $2^{\circ}$ Kamerzitting van 27 Nov. 1852 door het Kamerlid Rochussen werd opgehaald en in zijn konsekwenties verdedigd, is in den herdruk van 1860 versmolten in den hoofdtekst, p. 214-216.

Die Resident van Solo, dd. 26 Juni 1846 „eervol ontslagen, onder toekenning van waohtgeld" (aldus de Jav. Courant van 1846, No 44), was... de vroegere Resident van Kĕdoe en gastheer van Van Hoëvell, C. L. Hartisans; de G.-G. welke hem ongevraagd zijn congé gaf in dat jaar, was Rochussen; de G.-G. die bij Besluit van 3 Aug. 1848 aan Van Hoëvell óók ongewenscht zijn congé had gegeven, als Indisch predikant, was Rochusskx; het $2^{\bullet}$ Kamerlid 
Maar ook voor dengeen, die nog niet geheel overtuigd mocht wezen dat de schrijver van het Reisjournaal uit kwansuis 1839 inderdaad VAN HOËVELL was in 1840, zijn hier nog een paar bewijzen te vinden. Op p. 158 heft het verhaal "Een dorp en een berg" aldus aan: "Hadt gij den $3^{\text {den }}$ Mei $1840 \mathrm{mij}$ vergezeld,, - wat dan uitloopt op een beschrijving zijner afdaling op dien dag van de afdeeling Lędok naar Poerworědjo, de hoofdstad van Bagělen; en in zijn Reisjournaal van "1839» daalt de anonymus «den $3^{\text {den }}$ Mei» aleveneens uit de afdeeling Lědok, waar hij een 6 tal dagen bij den assistent-resident te Wonosobo had gelogeerd, af naar Poerworedjo (T. v. N.-I., 1860, I, p. 203). Op p. 139 was voorts VAN HOËVELL gaan vertellen over een tijgergevecht c't geen ik den 28 Mei 1840 te Soerakarta heb bijgewoond, en verwijst dan in een noot naar een uitvoerige beschrijving van "dit tijgergevecht», door hem gepubliceerd in het T. v. N.-I., $3^{\text {en }}$ jrg. (1840), I, p. $298-310^{1}$; ook onder zijn vollen naam. Dit laatste had plaats sop een Donderdagmorgen» (l. c. p. 300); en nu viel inderdaad 28 Mei 1840 op een Donderdag; dit zou dus mooi kloppen; maar toch is de datum fout, want op dien dag was VAN HOËvell nog... de gast van Resident Hartmann te Maǧlang, en vertrok pas op 29 Mei in oostelijke richting, samen met zijn gastheer, langs «de rivier Pabélan» (T. v. N.-I, 1860, I, p. 230) over het zadel tusschen Merapi en Merbaboe, natuurlijk... naar Solo (verg. hiervóór noot 2 op blz. 594); de datum moet dus vermoedelijk gelezen worden als 30 Mei 1840, zijnde een Zaterdag, d.w.z. de gebruikelijke weekdag in de Vorstenlanden weleer voor een toernooi (šeton van «Sětoe, Sěptoe») of eventueel een tijger- of buffel-gevecht. ${ }^{2}$

dat in Nov. 1852 de zaak van 1846 oprakelde en verdedigde, was de conservatieve oud-G.G. Rochussen; het $2^{\circ}$ Kamerlid, dat daarop zijn geachten collega aanviel, was de liberale ex-predikant van HoËverl! Men leze de Handelingen Staten-Generaal 1852/53, fol. 227 (rede-Rochussen), 231-232 (repliek-Van Hoëvell), 234 (dupliek-Rochussen); en lache!

1 De beschrijvingen van "dit tijgergevecht" zijn niet gelijk, zooals men uit het zeggen van den in zijn woorden - evenals in zijn kleeding - vaak nonchalanten $V_{A N}$ HoËvkLL zou opmaken. In de uitgaaf van 1840 wordt eerst beschreven het gevecht van een karbouw („buffel") met 2 tịgers, met daarop een rampok-partij van 4 tijgers, alles op denzelfden dag te Solo. In zijn "Uit het Indische leven" van 1860 zegt (en jokt!) VAN Hö̈vell, dat hij het eerste had bijgewoond "in 1843 te Djokjokarta" (p. 133), het tweede met 5 tijgers op 28 Mei 1840 te Solo.

, Of hier bij dat foutieve „28 Mei" 1840 aan een slordigheidje of een 
Ten slotte: in ditzelfde deel I van het T. v. N.-I. uit 1840 , gaan aan de hiervóór (noot 3 op blz. 594) reeds genoemde "Gedachten, over de Jav. Hindoe-rünen van Resident VALCK, aan het slot gedateerd "Djocjokarta, 11 Mei 1840», onmiddellijk vooraf 2 stukjes van vaN HOËvELL-zelf, een over «Wreede strafoefeningen vroeger op Java in gebruik», opgemerkt "op mijne laatste reis», en een over «Heilige Graven»; welke thans, door het in 1860 gepubliceerde Reisjournaal van den doorzichtigen anonymus, gedateerd kunnen worden als beschrijvend zijn ervaring op de grens van Tégal en Banjoemas dd. 19 April 1840, en zijn bezoek aan 't graf van Sultan Tegal Aroem (Soenan Mangkoerat I) nabij Tegal dd. 17 April te voren.

Eén ding blijft zeer jammer: dat in 1860 zijn beschrijving van Tjandi Sewoe uit 1840 werd weggelaten. Misschien, omdat Van Hoëvell haar later nog afzonderlijk wilde drukken, evenals hij reeds in 1858 met die van Boroboedoer had gedaan? Ook wilden wij graag zijne terugreis alsnog kennen, via Soerakarta (zie boven), en natuurlijk verder Sermarang. Maar wààr zijn de hss. van VAN HOËVELL na zijn dood op 10 Febr. 1879 gebleven?

Noch zijn persoonlijke sociëteits-vriend, alias "boezemvriend, VAN SOEST heeft het verteld in zijne biografie van vele woorden en vele aanhaalsels in het T. v. N.-I. 1879, II, p. 1-72 (met portret); noch helaas zijn levens- en geestesvriend VETH in diens rijke en edele biografie, afgedrukt in den bunde! "Ontdekkers en onderzoekers. Zevental levensschetsen» (1884), p. 234-294. Ook in den auctie-catalogus van zijn boekerij, bij de firma Nijhoff te Den Haag op 22 Nov. '79 en volgende dagen verkocht, vindt men enkel op p. 85 een dozijn Maleische hss. vermeld.

foefje van VAN HoËvell uit 1860 moet gedacht worden, blijft onzeker, zoolang het hs. niet opduikt. Vertrouwt men op den „Donderdag” van de beschrijving uit 1840, met zijn vollen naam geteekend, dan moet Do. 4 Juni 1840 als de ware datum beschouwd worden.

Op p. 111 komt dan in het hoofdstuk "Natuurtafereelen van Java" het jokkentje voor, dat hij in "1839" Karang Bolong met zijn vogelnestklippen bezocht; lees: op 8 Mei 1840, zooals blijkt uit het Reisjournaal, ed. 1860, p. 209-211. Op p. 101-103 had VAN HoËvell reeds zijn bezoek aan de bron der Progo-rivier, op de helling van den Sĕndoro, beschreven, hetgeen blijkens het Reisjournaal, p. 229, plaats had gevonden op 28 Mei 1840, den dag yóór zijn vertrek uit Magĕlang.

Het „28 April" op p. 178 van het Reisjournaal, ed. 1860, is echter een drukfout; lees: 23 April. 